\title{
A CLINICO-MYCOLOGICAL STUDY OF OTOMYCOSIS FROM A TERTIARY CARE HOSPITAL IN WESTERN UTTAR PRADESH
}

\author{
Sanjiv Ahuja1 , Anshul Bansal2, Anita Pandey33, Molly Madan4, Deepak Kumar Gupta ${ }^{5}$ \\ ${ }^{1}$ Associate Professor, Department of Microbiology, Subharti Medical College, Meerut. \\ ${ }^{2}$ Associate Professor, Department of ENT, Subharti Medical College, Meerut. \\ 3 Professor, Department of Microbiology, Subharti Medical College, Meerut. \\ 4 Professor \& HOD, Department of Microbiology, Subharti Medical College, Meerut. \\ ${ }^{5} 2^{\text {nd }}$ Year M. Sc. Student, Department of Microbiology, Subharti Medical College, Meerut.
}

\section{ABSTRACT}

\section{BACKGROUND}

The term otomycosis simply refers to superficial fungal infection of the external auditory canal. Most patients suffering from early otomycosis complain of severe itching which often progress to pain, hearing loss and tympanic membrane perforation.

Aims- To determine the predisposing factors, symptoms and to identify the fungus and secondary bacterial infection associated with it.

\section{MATERIALS AND METHODS}

A total of 100 consecutive patients with clinical diagnosis of otomycosis were considered as the study group and 100 consecutive patients with no diagnosis of otomycosis were considered as the control group from a total of 200 individuals attending the Outpatient Department of ENT at Chhatrapati Shivaji Subharti Hospital (CSSH), a tertiary care teaching hospital in Meerut City, were chosen for the study.

\section{RESULTS}

History of wooden stick or any other object used to remove wax (68\%), use of oil (44\%), swimming (28\%) and history of trauma (23\%) were the common predisposing factors in otomycosis. Pruritus and otalgia ( $89 \%$ each) were the most common complaints. Statistical association ( $\mathrm{p}$ value $<0.001$ ) was found between isolation of fungi and otomycosis whereas no statistical association was found between otomycosis and bacterial association. The fungi isolated were mainly Aspergillus niger (77.0\%) followed by A. flavus (12.6\%), A. terreus (4.6\%), Candida guilliermondii and C. krusei (1.1\% each). Bacterial isolates were Staphylococcus epidermidis (21\%), S. aureus (7\%), Klebsiella pneumoniae (2\%) and Enterobacter aerogenes (1\%). Fungal pathogens were isolated from external auditory canal of $8 \%$ of controls.

\section{CONCLUSION}

Pruritis and otalgia (89\% each) were the common complaints followed by discharge, tinnitus and hearing loss. Aspergillus (94.2\%) was the most common isolate from otomycosis in our study, followed by Candida (2.3\%) as in studies across the world. Isolation of Aspergillus spp. such as A. terreus isolate is important, as they are largely resistant to antifungal drug Amphotericin B. It usually resolves with aural toilet and installation of antifungal drugs. Recurrence of the disease is common after treatment. We had a recurrence rate of $20 \%$ as compared to $5 \%$ quoted in literature. This may be due to patients having poor hygiene, diabetes mellitus, community bathing and poor compliance to treatment.

\section{KEYWORDS}

Fungi, Aspergillus, A. Niger, Candida.

HOW TO CITE THIS ARTICLE: Ahuja S, Bansal A, Pandey A, et al. A clinico-mycological study of otomycosis from a tertiary care hospital in western Uttar Pradesh. J. Evolution Med. Dent. Sci. 2017;6(45):3493-3497, D0I: 10.14260/Jemds/2017/754

\section{BACKGROUND}

Otomycosis is derived from the Greek word Oto which means ear and mycosis means fungal, i.e. superficial fungal infection of external auditory canal. ${ }^{1}$ Otomycosis is one of the common disease seen in ENT OPD and its prevalence ranges from $6.54 \%-85 \% .1,2$ It is more prevalent in tropical and

Financial or Other, Competing Interest: None.

Submission 01-05-2017, Peer Review 25-05-2017,

Acceptance 31-05-2017, Published 05-06-2017.

Corresponding Author:

Dr. Sanjiv Ahuja,

Associate Professor,

Department of Microbiology,

Subharti Medical College,

Meerut-250005, Uttar Pradesh.

E-mail: ahujasanjiv2011@gmail.com

DOI: $10.14260 /$ jemds $/ 2017 / 754$

(c) $(1)$ subtropical areas because of the hot, humid and dusty environment. ${ }^{2}$ Multiple and prolonged use of broad spectrum antibiotics, trauma, persistent otorrhoea and swimming have been documented as predisposing factors.,3,5 Although literature search reveals Aspergillus niger as the most common agent of otomycosis, a wide variety of other fungi can cause otomycosis. 1,2,6,7,8 Despite the fact that our climatic conditions may encourage otomycosis, there is a dearth of literature and limited knowledge on this disease entity in our environment, hence, the need to create awareness among healthcare providers and the entire populace on this disease. Therefore, the study was carried out with the objective to determine the predisposing factors, symptoms, and to identify the fungus and secondary bacterial infection both in the study and control groups. 


\section{MATERIALS AND METHODS}

A total of 200 individuals attending the Outpatient Department of ENT at Chhatrapati Shivaji Subharti Hospital (CSSH), a tertiary care teaching hospital in Meerut City were chosen for the study. The study was carried out for a period of six months from 22 $2^{\text {nd }}$ June 2016 to 21 $1^{\text {st }}$ December 2016. The case control study was planned because fungi are also isolated from healthy ears. ${ }^{6}$ Approval from the Institutional Ethical and Research Committee was obtained before conducting the study.

\section{Inclusion Criteria}

100 cases with clinically diagnosed otomycosis were included in the study group. The diagnosis was based on the following symptoms (Itching, hearing loss, tinnitus, ear discharge, pain) and signs (on otoscopic examination: hyphae/spores were seen \&/or curdy discharge). 100 patients with no aural complaints attending ENT OPD were taken as controls.

\section{Exclusion Criteria}

The following condition was excluded from the study: patients with history suggestive of fungal diseases elsewhere in the body.

\section{Sample Collection}

Three sterile cotton tipped swabs were transported to the laboratory within half an hour for mycological and bacteriological examination. Consent was taken from all patients involved in the study.

\section{Processing}

One swab was cultured on Blood and MacConkey's agar at $37^{\circ} \mathrm{C}$ and examined for bacterial growth after 18-24 hours. Second swab was digested on a microscopic slide with $10 \%$ potassium hydroxide preparation. ${ }^{9}$ A $18 \mathrm{~mm} \times 18 \mathrm{~mm}$ number 1 coverslip was placed on the digested material and examined microscopically using $10 \mathrm{X}$ and $40 \mathrm{X}$ objectives for fungal elements. The third swab was inoculated on two Sabouraud's dextrose agar (SDA) tubes. One of the SDA tubes was incubated at $25^{\circ} \mathrm{C}$ and the other at $37^{\circ} \mathrm{C}$ for 3 weeks. Cultures were examined for growth on alternate days. Fungi were identified by standard procedures. ${ }^{10}$ Candida species were identified on the basis of germ tube formation, morphological identification on corn meal agar (HiMedia); colour differentiation on HiCrome Candida Differential agar (HiMedia) and sugar fermentation. ${ }^{11}$

\section{Statistical Analysis}

SPSS software version 19.0 (IBM, SPSS statistics) was used for statistical analysis. Chi-square test was performed for data analysis. The p-values below 0.001 were considered to be significant.

\section{RESULTS}

\section{Age, Sex and Occupation}

The highest incidence of otomycosis was in the group of 3140 years and the lowest was in the age group of less than 10 years [Table 1]. Most of the cases of otomycosis were found in students (29\%).

\section{Side and Laterality}

Otomycosis was predominantly unilateral both in males and females. Only 1\% presented with bilateral infection. In males the distribution was almost equal in both ears (Right ear $52.9 \%$ and left ear $47.1 \%$ ) and in females (33/49 cases, $67.3 \%$ ) right ear was more commonly involved. Overall, right ear was involved in $60 \%$ cases.

\section{Predisposing Factors}

The highest incidence of otomycosis was seen in patients with habitual cleansing of the ear with wooden stick or any other object to remove wax from ear $(68 \%)$ as shown in Table 2 .

\section{Clinical Features}

Pruritis and otalgia (89\% each) were the most common complaints followed by discharge $(79 \%)$, tinnitus $(70 \%)$ and hearing loss (61\%) as shown in Table 3. On otoscopy, masses of hyphae/ spores were seen in $67 \%$ patients and curd like grey/white discharge in $57 \%$ of patients.

\section{Associated Systemic Illness}

The common predisposing factors to immunosuppression noted in our study were chronic suppurative otitis media (22\%), diabetes mellitus (21\%), tuberculosis (4\%) and other granulomatous disease (lepromatous leprosy).

\section{Microbiology}

Out of 100 samples, 79 samples were both KOH preparation and fungal culture positive. True positives were $79 \%$ and true negatives were $5 \%$ by $\mathrm{KOH}$ preparation when compared to culture as shown in Table 4. The sensitivity, specificity, positive predictive value, negative predictive value and accuracy of $\mathrm{KOH}$ preparation when compared to culture were 90.8\% (82.89-95.27), 38.46\% (17.71-64.48), 90.8\%, 38.4\% and $0.84 \%$. Fungi were isolated from $87 \%$ of the study group who were diagnosed clinically to have otomycosis. The species of Aspergillus was isolated in $94.2 \%$ of the cases (82/87 cases). Out of 87 fungi isolated, A. niger (77.0\%) was the most common species followed by A. flavus (12.6\%), A. terreus (4.6\%), C. guilliermondii and C. krusei (1.1\% each). Of the three cases, two had coexisting A. niger and C. tropicalis infection $(2.3 \%)$ and one had coexisting A. flavus and A. fumigatus infection (1.1\%). Fungi were isolated from $8 \%$ of the healthy external auditory canal (controls). Significant association ( $p$ value $<0.001$ ) was found between study group of otomycosis and fungal isolation. In both the groups, Staphylococcus epidermidis was the most common bacteria isolated [Table 5]. No significant association ( $p$ value $>0.001$ ) was found between study group of otomycosis and bacterial association.

\begin{tabular}{|c|c|c|c|}
\hline Age & Sex & $\begin{array}{c}\text { Study Group } \\
\text { (Otomycosis) }\end{array}$ & $\begin{array}{c}\text { Control } \\
\text { Group }\end{array}$ \\
\hline \multirow{2}{*}{$\leq 10$ Years } & Male & 2 & 8 \\
& Female & 3 & 2 \\
\hline \multirow{2}{*}{$11-20$ Years } & Male & 9 & 10 \\
& Female & 8 & 6 \\
\hline \multirow{2}{*}{$21-30$ Years } & Male & 10 & 20 \\
& Female & 15 & 4 \\
\hline \multirow{2}{*}{$31-40$ Years } & Male & 16 & 3 \\
& Female & 11 & 5 \\
\hline \multirow{2}{*}{$41-50$ Years } & Male & 6 & 4 \\
& Female & 3 & 2 \\
\hline \multirow{2}{*}{$51-60$ Years } & Male & 4 & 10 \\
& Female & 5 & 4 \\
\hline \multirow{2}{*}{$>60$ Years } & Male & 4 & 13 \\
& Female & 4 & 9 \\
\hline \multirow{2}{*}{ Total } & Male & $\mathbf{5 1}$ & $\mathbf{6 8}$ \\
& Female & 49 & 32 \\
\hline \multicolumn{2}{|c|}{ Table 1. Demographic Profile of the Subjects } \\
in the Study (Otomycosis) and Control Group \\
\hline \multicolumn{4}{|c}{}
\end{tabular}




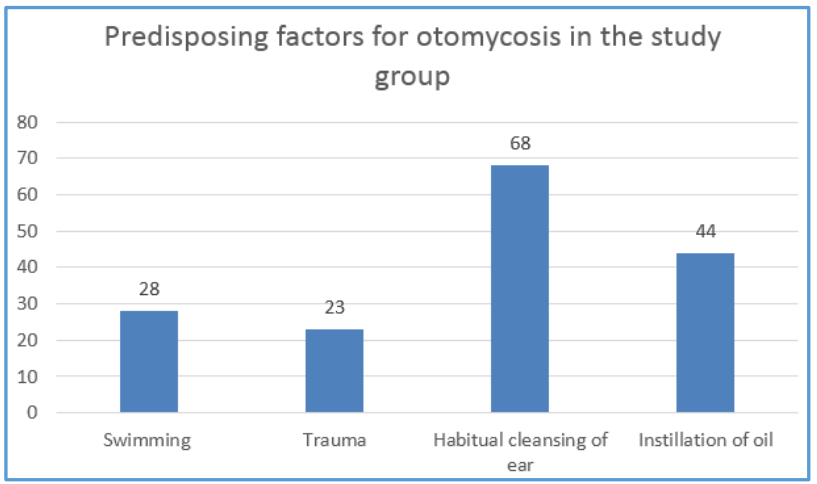

Table 2. Predisposing Factors of Otomycosis in the Study Group

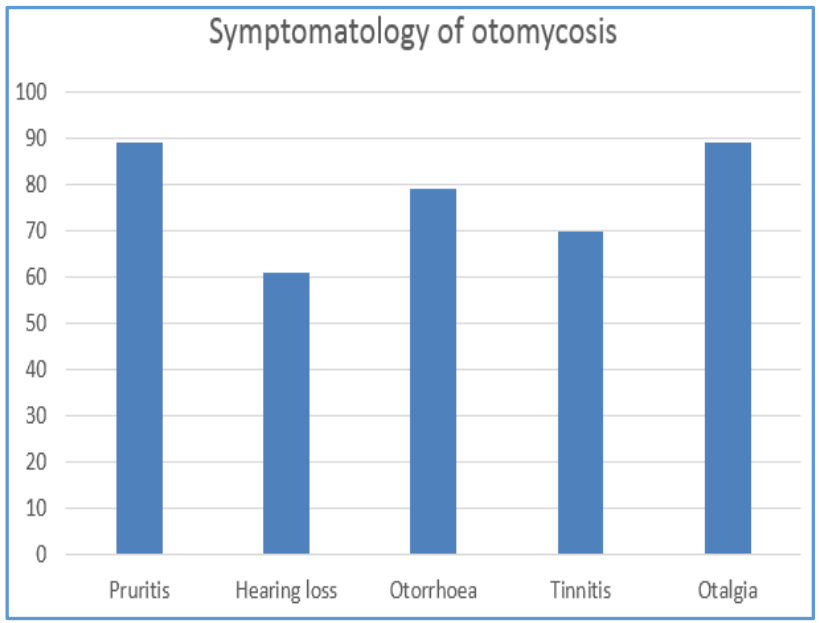

Table 3. Symptomatology of Otomycosis

\begin{tabular}{|c|c|c|c|}
\hline Positivity & Culture Positive & Culture Negative & Total \\
\hline KOH Positive & 79 & 8 & 87 \\
\hline KOH Negative & 8 & 5 & 13 \\
\hline Total & $\mathbf{8 7}$ & $\mathbf{1 3}$ & $\mathbf{1 0 0}$ \\
\hline Table 4. Sensitivity and Specificity of KOH Preparation when Compared to Culture (Gold Standard) \\
\hline
\end{tabular}

Sensitivity (95\% confidence interval): 90.8\% (82.89-95.27), Specificity (95\% confidence interval) l: 38.46\% (17.71-64.48).

\begin{tabular}{|c|c|c|c|c|c|c|}
\hline \multirow{2}{*}{$\begin{array}{l}\text { Fungal } \\
\text { Isolated }\end{array}$} & \multicolumn{2}{|c|}{ Study Group (100) } & \multicolumn{2}{|c|}{ Control Group (100) } & $\begin{array}{l}\text { Study Group } \\
(n=100)\end{array}$ & $\begin{array}{c}\text { Control Group } \\
(n=100)\end{array}$ \\
\hline & $\begin{array}{l}\text { No. of Cases } \\
\text { Positive for } \\
\text { Fungi (\%) }\end{array}$ & $\begin{array}{l}\text { No. of Cases } \\
\text { Positive for } \\
\text { Bacteria (\%) }\end{array}$ & $\begin{array}{l}\text { No. of Cases } \\
\text { Positive for } \\
\text { Fungi (\%) }\end{array}$ & $\begin{array}{l}\text { No. of Cases } \\
\text { Positive for } \\
\text { Bacteria (\%) }\end{array}$ & \multicolumn{2}{|c|}{$\begin{array}{c}\text { No. of Associated } \\
\text { Bacterial Isolates, } \\
\text { Number (\%) }\end{array}$} \\
\hline A. niger & $67(67)$ & $20(29.8 \%)$ & 0 & - & \begin{tabular}{|l|} 
S. epidermidis $15(22.4)$ \\
S. aureus $4(6.0 \%)$ \\
Klebsiella $1(1.5)$
\end{tabular} & \\
\hline A. flavus & $11(11)$ & $5(45.4)$ & $2(2)$ & $0(0)$ & \begin{tabular}{|l|} 
S. epidermidis $2(40)$ \\
S. aureus $1(20)$ \\
Klebsiella spp. $1(20)$ \\
Enterobacter $1(20)$
\end{tabular} & \\
\hline A. terreus & $4(4)$ & $2(50)$ & 0 & - & S. epidermidis $2(50)$ & \\
\hline C. albicans & 0 & - & $2(2)$ & $2(100)$ & $x^{-}$ & $\begin{array}{c}\text { S. epidermidis } \\
1 \text { (50); Klebsiella } \\
1(50)\end{array}$ \\
\hline C. tropicalis & 0 & - & $4(4)$ & $2(50)$ & - & $\begin{array}{l}\text { S. epidermidis } \\
1(25) \\
\text { S. aureus } 1(25)\end{array}$ \\
\hline C. guilliermondii & $1(1)$ & $1(100)$ & 0 & - & S. aureus $1(100)$ & \\
\hline C. krusei & $1(1)$ & $0(0)$ & 0 & - & - & - \\
\hline $\begin{array}{l}\text { Mixed fungal } \\
\text { infection }\end{array}$ & $3(3)$ & $1(33.3)$ & 0 & - & S. aureus 1 (33.3) & \\
\hline No growth & $13(13)$ & $2(15.4)$ & 92 & $23(25)$ & $\begin{array}{l}\text { S. epidermidis } \\
2(15.4)\end{array}$ & $\begin{array}{c}\text { S. epidermidis } 20 \\
(21.7) \\
\text { S. aureus } \\
2(2.2) ; \\
\text { P. aeruginosa } \\
1(1.1)\end{array}$ \\
\hline & Table 5 F & Bacteria As & tion in the & y (Otomyco & and Control Group & \\
\hline
\end{tabular}

\section{DISCUSSION}

Otomycosis is a superficial infection of external auditory ear, and is worldwide in distribution, but is more common in tropical areas because of hot and humid weather.

\section{Age, Sex and Occupation}

Our study is comparable to a study from Tamil Nadu where most of the cases occurred in 30-40 years of age whereas in studies from Karnataka most of the cases were reported in 21-30 years age group.1,6,12 Studies from Karnataka and 
Pakistan have reported it to be more common in males as in our study. 1,6,7,13 whereas studies from Nigeria, Brazil, Iran, Shanghai and Haryana have reported it to be more common among young females. ${ }^{2.14}$ In our series, the ratio was 1.04:1. In our series, most of them were students while in another study from Mangalore it was found in persons engaged in agriculture related jobs. ${ }^{6}$ Students spend most of the time outdoors and aspergilli are common air saprophytes.

\section{Side and Laterality}

Overall, the disease was unilateral, and unilateral is less infectious than bilateral.1,6 In females, the right ear was commonly involved whereas in males, both ears were equally involved as in another study. ${ }^{6}$

\section{Predisposing Factors}

The predisposing factors seen in our study were use of wooden stick or any other object to remove wax from ear, use of oil, swimming \& history of trauma. In patients with poor personal hygiene, excessive cerumen was present which favoured the germination of spores and conidia of prevalent fungi. ${ }^{15}$ Practices like addictive exploitation of the external ear with any hard object such as wooden stick, hair-pin, safety-pin, feather cause trauma (usually minor) to the skin. This leads to deposition of fungal conidia in the wound leading to fungal infection.

\section{Clinical Features}

Pruritis was the most common complaint as seen in other studies. ${ }^{1,6}$ Other complaints were otalgia, otorrhoea, tinnitus and hearing loss.

\section{Associated Systemic Illness}

Immunocompromised patients are known to be more prone to otomycosis. ${ }^{2}$ In our study, $21 \%$ of cases have history of diabetes mellitus which was higher than other studies which showed $6.08 \%$ and $16 \% .2,7$

Recurrence of the disease is common after treatment. We had a recurrence rate of $20 \%$ as compared to $5 \%$ quoted in literature.2,15 This may be due to diabetes mellitus, community bathing, patients having poor hygiene and poor compliance to treatment. Hyperglycaemia usually provides a good culture environment for fungus, hence the need to have a normal blood sugar level.

\section{Investigation and Organisms}

Microscopic examination and culture are required to confirm the diagnosis. Aspergillus niger was the most common fungi isolated in our study, and was in in concordance with other studies. ${ }^{1,2,6,16}$ Clinically, it is important to identify Aspergillus species as Aspergillus terreus is largely resistant to the antifungal drug Amphotericin B. As there is abundance of proteins, carbohydrates, favourable humidity and temperature, the external auditory canal is an ideal site for microorganisms to grow. ${ }^{14}$ In our study, $87 \%$ of patients suspected to have otomycosis were confirmed. It is slightly higher than other studies.1,17,18 It may be because of quick diagnosis and processing of the samples. Eight samples which were positive by $\mathrm{KOH}$ preparation did not show growth on culture media, probably because of delay in processing of these samples.
Staphylococcus epidermidis were found in external auditory canal as they are the most common commensals of skin. Commensals of other parts of body and transient flora may flourish when the natural defence mechanism breaks down as in otitis externa.

In the control group, fungi were seen in $8 \%$ of the normal ears. The order of isolation of fungi from healthy external ear was not similar to cases seen in otomycosis. C. tropicalis, C. albicans \& A. flavus were isolated. It could be due to a decreased host barrier in the skin due to minor trauma during ear cleaning, itching. Factors like poor sanitation, poor nutrition or physical factors like increased regional temperature or humidity may also tilt the balance towards the growth of fungus. Such patients may develop otomycosis in due course if favouring condition persists.

\section{Treatment}

Treatment involves elimination of predisposing factors. All patients diagnosed with otomycosis were subjected to thorough ear toilet by dry mopping and manual removal of fungus by Jobson Horne probe with cotton swab or suction and irrigation followed by instillation of $1 \%$ clotrimazole antifungal ear drops, 3-4 drops every 6 hours for 7 days. In case of persistence of disease or recurrence, systemic antibiotics (Cefixime $200 \mathrm{mg}$ every 12 hourly) along with Broad spectrum ear drops (Ofloxacin + Clotrimazole+ Beclomethasone) 3-4 drops every 6 hours for 7 days to be used. Clotrimazole has an antibacterial effect, and this is an added advantage when treating mixed bacterial-fungal infections. ${ }^{19}$

\section{Limitations}

Molecular methods like DNA sequence based identifications methods were not used because they involve significant cost and phylogenetic expertise.

\section{CONCLUSION}

In the present study, fungi were isolated from $87 \%$ of the patients with clinical diagnosis of otomycosis. A. niger (77\%) is found to be the commonest aetiological agent causing otomycosis. Habitual cleansing of the ear with wooden stick or any other object (68\%) has been found to be the most common predisposing factor, and pruritis and otalgia $(89 \%$ each) were the most common clinical presentations. As $87 \%$ of fungi are isolated in suspected cases, early diagnosis and treatment with $1 \%$ clotrimazole is needed. Recurrence is not uncommon, and we had a recurrence rate of $20 \%$.

\section{ACKNOWLEDGEMENT}

We acknowledge the efforts of the statistician, Mr. Arvind Shukla.

\section{REFERENCES}

[1] Gokale SK, Suligavi SS, Baragundi M, et al. A Cinicomycological study. International J Med Health Sci 2013;2(2):218-23.

[2] Fasunla J, Lbekwe T, Onakoya P. Otomycosis in western Nigeria. Mycoses 2008;51(1):67-70.

[3] Kurnatowski P, Filipiak A. Otomycosis: prevalence, clinical symptoms, therapeutic procedure. Mycoses. 2001;44(11-12):472-9. 
[4] Jackman A, Ward R, April M, et al. Topical antibiotic induced otomycosis. Int J Pediatr Otorhinolaryngol 2005;69(6):857-60.

[5] Martin TJ, Kerschner JE, Flanary VA. Fungal causes of otitis externa and tympanostomy tube otorrhea. Int J Pediatr Otorhinolaryngol 2005;69(11):1503-8.

[6] Prasad SC, Kotigadde S, Shekhar M, et al. Primary otomycosis in the Indian subcontinent: predisposing factors, microbiology, and classification. International Journal of Microbiology Article ID 636493, 2014;(2014):1-9.

[7] Satish HS, Vishwanatha B, Manjuladevi M. A clinical study of otomycosis. IOSR-JDMS 2013;5(2):57-62.

[8] Sarvan RR, Kilkani KM, Mehta SJ, et al. Clinicomycological study of otomycosis. Int J Biol Med Res 2012;3(4):2469-70.

[9] Collee JG, Miles RS, Watt B. Tests for identification of bacteria. In: Collee JG, Fraser AG, Marmion BP, et al, eds. Mackie and McCartney's practical medical microbiology. 14th edn. New York: Churchill Livingstone 1996:131-45.

[10] Fischer F, Cook NB. Some opportunistic fungi. In: Fischer F, Cook NB, eds. Fundamentals of diagnostic mycology. Philadelphia USA: WB Saunders 1998:35102.

[11] Chander J. Candidiasis. In: Chander J, ed. Textbook of medical mycology. $3^{\text {rd }}$ edn. New Delhi, India: Mehta Publishers 2010:266-90.
[12] Karn PK, Lakshmanan A, Hemamalini M, et al. Otomycosis: a study from a tertiary care hospital. Journal of Pharmacy Research 2014;8(3):266-8.

[13] Anwar K, Gohar MS. Otomycosis: clinical features, predisposing factors and treatment implications. Pak J Med Sci 2014;30(3):564-7.

[14] Barati B, Okhovvat SAR, Goljanian A, et al. Otomycosis in central Iran: a clinical and mycological study. Iran Red Crescent Med J 2011;13(12):873-6.

[15] Kaur R, Mittal N, Kakkar M, et al. Otomycosis: a clinicomycological study. Ear Nose Throat J 2000;79:606-9.

[16] Aneja KR, Sharma C, Joshi R. Fungal infection of the ear: a common problem in the north eastern part of Haryana. International Journal of Paediatric Otorhinolaryngology 2010;74:604-7.

[17] Pradhan B, Tuladhar NR. Amatya RM. Prevalence of otomycosis in outpatient department of otolaryngology in Tribhuvan University Teaching Hospital, Kathmandu, Nepal. Ann Otol Rhinol Laryngol 2003;112(4)384-7.

[18] Ozcan M, Ozcan MK, Karaaslan A. Concomitant otomycosis and dermatomycosis: a clinical and microbiological study. Eur Arch Otorhinolaryngol 2003;260(1):24-7.

[19] Munguia R, Daniel SJ. Ototopical antifungals and otomycosis: a review. Int J Pediatr Otorhinolaryngol 2008;72(4):453-9. 